\title{
Function Analysis of the Urban Green Space Disaster-prevention System Based on AHP
}

\author{
Chunyan Zhu' ${ }^{1, \text { a, }}$, Zhenglin Qiao ${ }^{2}$, Yizhi Jiang ${ }^{1}$, Yuedan Wang ${ }^{1}$ \\ ${ }^{1}$ College of Landscape Architecture, Sichuan Agricultural University, Chengdu, Sichuan Province, China \\ ${ }^{2}$ Southwest Forestry University, Kunming, Yunnan Province, China \\ a41243@sicau.edu.cn \\ *Corresponding author
}

Keywords: Green space system; Dujiangyan; function evaluation; analytic hierarchy process.

\begin{abstract}
Taking the rebuilt urban disaster-prevention green space system as the study object in Dujiangyan city, Sichuan province after the "5.12" Wenchuan Earthquake in 2008, this paper aims to establish the evaluation system that suits small-sized cities located on the seismic belts such as Dujiangyan. The study employs Analytic Hierarchy Process (AHP) and selects forty-nine closely relevant factors from the four main aspects: urban environment, the spatial structure, the layout of the urban disaster-prevention green space and the emergency shelters and facilities in Dujiangyan. The forty-nine factors are categorized into index and criteria level. Through a questionnaire survey, the study draws the objective assessment of the disaster-prevention function of the urban green space system in Dujiangyan from both qualitative and quantitative perspectives. Based on the analysis of the assessment results combined with the current hardware and software emergency facilities stats quo, this paper proposes strategies for the improvement and perfection of the disaster-prevention green space system in Dujiangyan.
\end{abstract}

\section{Introduction}

Dujiangyan city was severely damaged during the "5.12" Wenchuan Earthquake in 2008. After being reconstructed, the city's urban green space system was recovered and its disaster-prevention function has been improved. Dujiangyan is a typical small-sized city that is located on the seismic belt and taken as the object of this study, this paper has evaluated the disaster-prevention function of its urban green space system from both qualitative and quantitative perspectives in the hope of providing useful practical experience and suggestions on the reconstruction of disaster-prevention urban green space system in earthquake zones.

\section{Research Areas and Evaluation Method}

\subsection{Overview of research areas}

The city of Dujiangyan is located on the northwest edge of the Sichuan Basin and covers an area of $103^{\circ} 26^{\prime}-103^{\circ} 47^{\prime} \mathrm{E}$ and $30^{\circ} 45^{\prime}-31^{\circ} 22^{\prime} \mathrm{N}$. The city is internally connected by roads, rivers, irrigation channels and greenbelts together with the green ecological corridors of the five rivers, which form into a vertical connection network between the elements of "mountain-water-city-forest-weir-field" in the city.

The research area is defined within the scope of Dujiangyan city, which includes three parts: The Main City district, the Yutang district and the Juyuan district.

The Main city district locates in the north of Dujiangyan and expands to the city planning area in the east, and to the Jinma River in the west and Duwen Express way in the south. II. The Yutang district expands to the city planning area with its north, west and south and the Jinma River in the east. III. The Juyuan district expands to the city planning area with its west, south and east and to the 
Duwen Express way in the north. The urban construction land area is $45.80 \mathrm{~km} 2$ with $1732.02 \mathrm{hm} 2$ of the green space and $494.24 \mathrm{hm} 2$ of park green area respectively.

\subsection{Evaluation method}

First, establish the evaluation system based on AHP and measure the index weight. Through an expert's questionnaire survey with their expertise, all the factors that affect the disaster-prevention function of the urban green space in Dujiangyan were divided into four hierarchies with affiliation relationship. Each hierarchy was further divided into several elements. By comparing the weight of each element relative to last hierarchy, the order of priority of each element has been drawn to achieve the function evaluation goal. The full steps in order were - constructing structure of evaluation model based on experts' assessment, establishing judgment matrix, followed by the sequencing of single hierarchy and consistency check and the final sequencing of hierarchies and consistency check [1].

After the evaluation model was established, a questionnaire survey for the citizens was sent out. The survey results were analyzed by AHP which led to the function evaluation results.

\section{Construction of Evaluation System and Factor Weight Calculation}

\subsection{Model construction of the evaluation system}

Selection and Confirmation of Evaluation Factors. This paper protocols urban environment, the spatial structure of the urban disaster-prevention green space, the quantitative index of green space layout and the emergency shelters and facilities as four paralleled levels which influence disaster-prevention function of the urban green space system, based on the research results of relevant scholars and aspects of disaster-prevention function evaluation of the urban green space system. At the same time, more than 60 impact factors are put into questionnaires for experts titled Factors choosing of the Disaster-prevention Function Evaluation given to experts on green space research in Chengdu. After their marking, 49 impact factors are chosen to form an initial system structure. 28 questionnaires were issued in this survey, 21 were recovered and 21 were valid.

Construction of Evaluation System with Four Layers. The Evaluation System of the Disaster-prevention Function of the Urban Green Space consists of Goal Layer, Criteria Layer, Index Layer and Alternative Layer. The Alternative Layer consists of the 49 chosen impact factors. The four layers are in affiliation relationship, and each impact factor in one layer is paralleled.

The Goal Layer is to evaluate the disaster-prevention function of the urban green space, while the Criteria Layer consists of urban environment, the spatial structure of the urban disaster-prevention green space, the quantitative index of green space layout and the emergency shelters and facilities. In Index Layer there are 14 elements inferred from factors in Criteria Layer: natural environment, artificial environment, building system, disaster-prevention urban green space system, traffic system, disaster prevention park, temporary/emergency safety green space, segregation greenbelt, green escape channel, domestic installation, medical facility, traffic and communications, fire equipment and emergency software facilities, etc. The Alternative Layer consists of 49 impact factors chosen by the experts.

By paired comparison with factors respectively from Criteria Layer and Alternative Layer, the matrix, the largest eigenvalue ${ }^{\lambda_{\max }}$, weight, and $C R$ value for the consistency check are obtained and finally, the weight table of the evaluation system.

\subsection{Determination of evaluation factors' values and weights}

Weight Table. By using AHP, the evaluation modal finally has its evaluation factors and factors wight, (Table 1).

Evaluation Level. In this research, the marking scheme for evaluation ranges from 0 to 9. Marking and calculation result based on the evaluation system above is in $0-9$, too. (table 2 ) 


\section{Table 1: Weight calculation of the evaluation system of urban green space disaster-prevention function}

\begin{tabular}{|c|c|c|c|c|c|c|}
\hline Goal & Criteria & $\begin{array}{l}\text { Criteria } \\
\text { weight } \\
\text { (w) }\end{array}$ & Index & $\begin{array}{l}\text { Index } \\
\text { weight } \\
\text { (w) }\end{array}$ & Alternatives & $\begin{array}{l}\text { Alternative } \\
\text { weight (w) }\end{array}$ \\
\hline \multirow[t]{38}{*}{$\begin{array}{l}\text { Evaluation of the } \\
\text { Disaster-prevention } \\
\text { Function of the } \\
\text { Urban Green Space } \\
\text { System }\end{array}$} & $\begin{array}{l}\text { Urban } \\
\text { Environment (C1) }\end{array}$ & 0.0788 & $\begin{array}{l}\text { Natural Environment } \\
\text { (B1) }\end{array}$ & 0.5000 & Type And Distribution of Disasters (A1) & 0.5075 \\
\hline & & & & & Topography and Landform(A2) & 0.2771 \\
\hline & & & & & Hydrologic Condition(A3) & 0.0666 \\
\hline & & & & & Geologic Condition(A4) & 0.1489 \\
\hline & & & $\begin{array}{l}\text { Artificial Environment } \\
\text { (B2) }\end{array}$ & 0.5000 & Density of Population (A5) & 0.6370 \\
\hline & & & & & Urban Development(A6) & 0.2583 \\
\hline & & & & & Human Performance Pattern(A7) & 0.1047 \\
\hline & $\begin{array}{l}\text { The Spatial Structure } \\
\text { of the Urban } \\
\text { Disaster-Prevention } \\
\text { Green Space(C2) }\end{array}$ & 0.3623 & $\begin{array}{l}\text { Building System } \\
\text { (B3) }\end{array}$ & 0.1140 & Seismic Class of Buildings(A8) & 0.6370 \\
\hline & & & & & Density of Building Distribution (A9) & 0.2583 \\
\hline & & & & & Building Height (A10) & 0.1047 \\
\hline & & & $\begin{array}{l}\text { Disaster-Prevention } \\
\text { Urban Green Space } \\
\text { System (B4) } \\
\end{array}$ & 0.8142 & Amount and Scale of Green Space (A11) & 0.4571 \\
\hline & & & & & Green Space Layout (A12) & 0.0910 \\
\hline & & & & & $\begin{array}{l}\text { Relative Soundness of Green } \\
\text { Function(A13) }\end{array}$ & 0.1547 \\
\hline & & & & & $\begin{array}{l}\text { The Functional Equilibrium Of Green } \\
\text { Space(A14) }\end{array}$ & 0.0580 \\
\hline & & & & & $\begin{array}{l}\text { Green Space/Green channel connectivity } \\
\text { (A15) }\end{array}$ & 0.2401 \\
\hline & & & $\begin{array}{l}\text { Transportation System } \\
\text { (B5) }\end{array}$ & 0.0718 & Transport Road Hierarchy (A16) & 0.5370 \\
\hline & & & & & Density of Traffic Road Network (A17) & 0.2583 \\
\hline & & & & & Road Layout Pattern (A18) & 0.2047 \\
\hline & $\begin{array}{l}\text { The Layout Green } \\
\text { Space Quantitative } \\
\text { Index (C3) }\end{array}$ & 0.3274 & $\begin{array}{l}\text { Disaster Prevention } \\
\text { Park (B6) }\end{array}$ & 0.4043 & $\begin{array}{l}\text { Amount of Disaster Prevention Park } \\
\text { (A19) }\end{array}$ & 0.0677 \\
\hline & & & & & Area of Disaster Prevention Park (A20) & 0.2478 \\
\hline & & & & & Service Radius (A21) & 0.4539 \\
\hline & & & & & Per Capita Effective Area (A22) & 0.2306 \\
\hline & & & $\begin{array}{l}\text { Temporary/Emergency } \\
\text { Safety Green Space (B7) }\end{array}$ & 0.2703 & Capacity (A23) & 0.2583 \\
\hline & & & & & Uniform Distribution Degree(A24) & 0.1047 \\
\hline & & & & & Service Radius (A25) & 0.6370 \\
\hline & & & $\begin{array}{l}\text { Segregation Greenbelt } \\
\text { (B8) }\end{array}$ & 0.0738 & Width And Length Of Greenbelt (A26) & 0.2583 \\
\hline & & & & & Integrity of Defensive Circle (A27) & 0.6370 \\
\hline & & & & & $\begin{array}{l}\text { Reasonableness of Plant Configuration } \\
\text { (A28) }\end{array}$ & 0.1047 \\
\hline & & & $\begin{array}{l}\text { Green Escape Channel } \\
\text { (B9) }\end{array}$ & 0.2516 & Width and Length(A29) & 0.1246 \\
\hline & & & & & $\begin{array}{l}\text { Continuity of Green Escape Channel } \\
\text { (A30) }\end{array}$ & 0.2636 \\
\hline & & & & & Continuity of shelters (A31) & 0.0633 \\
\hline & & & & & $\begin{array}{l}\text { Distance between Buildings and } \\
\text { Planning Red Lines (A32) }\end{array}$ & 0.5485 \\
\hline & $\begin{array}{l}\text { The Emergency } \\
\text { Shelters And } \\
\text { Facilities (C4) }\end{array}$ & 0.2315 & $\begin{array}{l}\text { Domestic Installation } \\
\text { (B10) }\end{array}$ & 0.1969 & Toilet Amount and Distribution (A33) & 0.0900 \\
\hline & & & & & $\begin{array}{l}\text { Amount and Distribution of Water } \\
\text { Supply (A34) }\end{array}$ & 0.2400 \\
\hline & & & & & Area of Temporary Tent (A35) & 0.4571 \\
\hline & & & & & $\begin{array}{l}\text { Amount and Distribution of Storeroom } \\
\text { for Emergency Reserve (A36) }\end{array}$ & 0.1547 \\
\hline & & & & & $\begin{array}{l}\text { Amount and Distribution of Power Unit } \\
\text { (A37) }\end{array}$ & 0.0580 \\
\hline & & & Medical Facility(b11) & $257^{0.0}$ & Distribution of Medical Assistance (A38) & 0.1608 \\
\hline
\end{tabular}




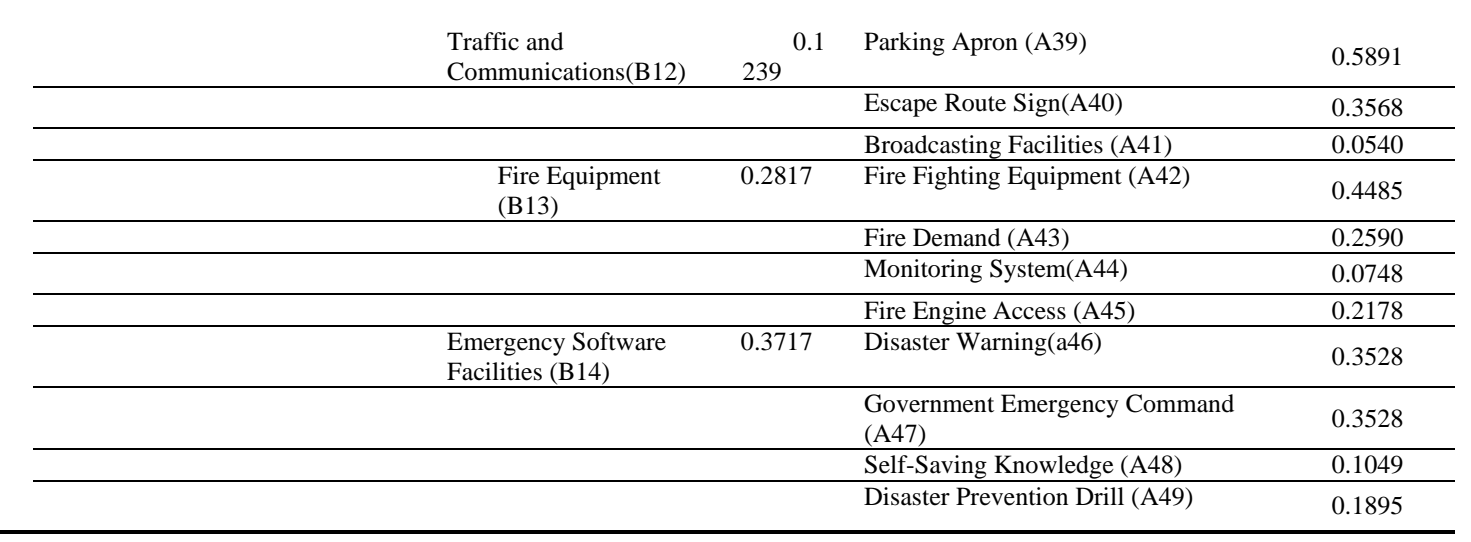

Table 2: Assessment level control

\begin{tabular}{ccccc}
\hline Level & Excellent & Good & Medium \\
\hline Details & With Excellent & With Good Disaster & With Medium \\
& $\begin{array}{c}\text { Disaster Prevention } \\
\text { Function }\end{array}$ & $\begin{array}{c}\text { Disaster Prevention } \\
\text { Prevention Function }\end{array}$ & $\begin{array}{c}\text { Disaster Prevention } \\
\text { Function }\end{array}$ \\
\hline Mark Range & Above 7 & $6-7$ & $5-6$ & Below 5 \\
\hline
\end{tabular}

\section{Evaluation of the Disaster-prevention Function of the Urban Green Space System in Dujiangyan}

\subsection{Data sources and sample}

Data sources of this research are from questionnaires and the Construction Bureau of Dujiangyan. 480 questionnaires were issued in the three target districts and each district with 160. 151, 147, 153 were recovered respectively in Yutang district, main city area, Juyuan district. In total, 451 were recovered and 451 were valid, the valid rate is $93.95 \%$. During the questionnaires respondents are chosen randomly, and their gender, age, education degree are out of consideration.

\subsection{Evaluation of the disaster-prevention function of the Dujiangyan urban green space}

Evaluation Criteria. According to the evaluation system that is established, when doing the evaluation, the importance of each evaluation impact factor is presented in 5 levels and relative marking criterion is listed in the questionnaires to make people's grading easier.

Analysis of Questionnaires. After statistics on the results of the questionnaires, scores of the Alternative Layer, Criteria Layer and Index Layer are calculated successively according to the weight of the evaluation system of urban green space disaster-prevention function. By operating the formula below:

$$
D_{b}=\sum_{1}^{n} C i W_{i}
$$

The score of level 0 is got.

Table 3: The Dujiangyan urban green space disaster-prevention score for level 0

\begin{tabular}{|c|c|c|c|c|}
\hline $\begin{array}{l}\text { Evaluation of the } \\
\text { Disaster-Prevention } \\
\text { Function of the } \\
\text { Urban Green Space } \\
\text { System }\end{array}$ & $\begin{array}{l}\text { Urban } \\
\text { Environment } \\
\text { C1(0.0788) }\end{array}$ & $\begin{array}{l}\text { Spatial Structure of } \\
\text { the Urban } \\
\text { Disaster-Prevention } \\
\text { Green Space } \\
\text { C2 }(0.3623)\end{array}$ & $\begin{array}{l}\text { Quantitative Index of Green } \\
\text { Space Layout C3(0.3274) }\end{array}$ & $\begin{array}{l}\text { The Emergency } \\
\text { Shelters and Facilities } \\
\text { C4(0.2315) }\end{array}$ \\
\hline Score & 5.0478 & 6.3128 & 7.7590 & 5.7901 \\
\hline Wight & 0.0788 & 0.3623 & 0.3274 & 0.2315 \\
\hline $\begin{array}{l}\text { Final Evaluation } \\
\text { Score }\end{array}$ & & & 6.5656 & \\
\hline
\end{tabular}




\section{Discussion}

\subsection{Evaluation results}

The score of Dujiangyan urban green space system disaster-prevention function is 6.5656. That is to say, Dujiangyan's green space system now has good disaster-prevention function. The layout of green space quantitative index is excellent; the spatial structure of the urban disaster-prevention green space is good, and the emergency shelters and facilities is medium, which means the most urgent thing is to improve the emergency shelters and facilities.

Taking both the situation of Dujiangyan fieldwork and the evaluation result into consideration, the following conclusions are got:

Dujiangyan is more at risk due to its special geographical location.

In general, the spacial structure of city disaster-prevention is good, but some traffic monitoring equipment should be improved.

The layout of Dujiangyan disaster-prevention urban green space is excellent.

Facilities of disaster-prevention green space system in Dujiangyan need to be improved urgently.

\subsection{Suggestions on construction of the urban green space system in Dujiangyan after Wenchuan Earthquake}

Grasp the post-disaster reconstruction opportunity to rearrange the residential land and population distribution reasonably.

The ability of supporting facilities in the green space should continue to be strengthened according to the expected usage in aspects such as energy supply equipment, emergency drinking water devices, lighting devices, sanitary fittings, emergency medical facilities, communication facilities and fire safety facilities [9].

Reform the original small green space timely to exert their ability of disaster-prevention.

Improve the awareness of people's sense of building and maintaining disaster-prevention green space, as well as the legal supervision.

Traffic roads at all levels of the city need to be cleaned, certain intelligent traffic management equipment should be supplied to make sure the road is accessible.

More publicity of urban green space disaster-prevention function and manoeuvre in certain site is needed to improve citizens knowledge and application ability.

\section{References}

[1] Lu Yumei, Ji Min. AHP-Research on Fuzzy Comprehensive Evaluation Method [J]. China Safety Science Journal,2004(7):86-89

[2] Hong Bo, Li Shuhua, Hu Lihui. Survey on Chengdu Green Space Function of Disaster Prevention After the Wenchuan Earthquake [J]. Safety and Environmental Engineering,2009,16(5). 